its appearance in the intestine may be explained somewhat as follows :-

The ovum, probably already fertilised in the infundibulum of the tube, fell from this into the peritoneal cavity-in the neighbourhood of the cæcum. The serosa assumed, as in the above-described case, the rôle of the uterine mucous membrane. The foetus developed, and around that there formed a connective tissue capsule-a pseudouterus. After some time the foetus died. Its nourishment and also that of its envelope gradually declined. Degenerative processes set in. Necrotic or atrophic processes and ultimate perforation took place between the pseudo-uterus and the wall of the cæcum, the latter possibly having been fixed and also compressed by the new growth. In this way there arose a communication between the fotal sack and the crecum. The intestinal contents also passed into this pseudouterus. Maceration and partial digestion of the bones took place. The smaller bones would mix with the cæcal contents, and with these leave the mother animal. The larger bones, on the contrary, remained behind till the moment of slaughter. But the whole of this process occupied a considerable time, so that it may be taken as highly probable that the two foetuses were not proper twins, but that the one formed external to the uterus was essentially older than the normal one.

This case would thus render plausible not only the possibility of the birth of an extra-uterine developed fotus through the intestine, but also that an animal already pregnant may again be impregnated.

\title{
ENLARGEMENT OF THE THYROID GLAND IN YOUNG LAMBS.
}

By Finlay Dun, F.R.C.V.S., Edinburgh.

Mr Thomas Ferguson, Middleton, Belford, Northumberland, on the 8th April I890, forwarded to me the head and neck of a half-bred lamb, stated to be about ten days old, and which from birth had suffered from difficulty of breathing and swallowing. The case evidently being an uncommon one, I took the specimen to Professor $M$ 'Fadyean, who pronounced it to be enlargement of the thyroid gland, had the subjoined drawing made of it, examined the swelling microscopically, and appends the following report of his observations.

$\mathrm{Mr}$ Ferguson informs me that half a score of lambs had been affected in the same manner as that forwarded. The prominent symptoms had been cough, which was aggravated when the patient was moved, and there was a good deal of swelling appeared about the angle of the jaw. Several lambs had been ailing at birth and others shortly became affected; none of those attacked recovered, most of them died within ten days or a fortnight.

Although thirty-two years in his present farm, Mr Ferguson, until the present spring, has not had any such disease in his flock. On a neighbouring farm, however, six or eight lambs, he states, died apparently from the same disease during the spring of 1889 , while a still more extended outbreak occurred five years previously. 
The lambs recently affected are reported to be half-bred, are of both sexes, and the produce of one tup bought last autumn at Kelso, from an old established Border Leicester flock. Examination of the ram does not discover any difficulty in his breathing or swallowing, or any fulness about his throat. This is his first crop of lambs, one-third of which have been attacked, but he will not again be used. No disease having occurred amongst the lambs got by the other Middleton rams, suggests the presumption that the glandular enlargement was hereditary, and this view is supported by Mr Ferguson's neighbour, who states that the ram which sired his lambs which were affected five years ago was found on examination to have a fulness about the throat, similar to that which killed the progeny.

Enlargement of the thyroid, known in human patients as goitre, broncele, or Derbyshire neck, is believed to result from the drinking of hard water; but both farms on which these lambs have been affected are stated to be well supplied with soft water, the Middleton flock having access to watcr derived from whinstone, freestone, and peat. Were the water, however, the chief cause of these Northumbrian goitrous outbreaks, it is very unlikely that young lambs, tasting scarcely anything but their mother's milk, should have been the only animals attacked on either of the two farms.

This report may, perhaps, bring to light other cases of enlarged thyroid in the lower animals, and elicit information as to its causes.

[Veterinary literature contains very little information of a precise or trustworthy character concerning diseases of the thyroid gland in the lower animals. Many of the older references to so-called goitre of the lower species lose the whole of their value, inasmuch as there can be no doubt that the term has frequently been applied with great looseness to enlargements of all kinds occurring in the region of the throat and upper part of the neck. In this way it is almost certain that tubercular enlargement of the lymphatic glands and actinomycosis have sometimes had the term goitre applied to them. As an illustration of the dearth of information regarding goitre in our domesticated animals, it may be observed that the condition is not mentioned in Williams' Text-book of Veterinary Medicine (Ist Edition, 1874) or in Friedberger and Frohner's excellent treatise on the same subject (Ist Edition, 1887). In the Lancet for I 887, Dr A. T. Sloan in an article on goitre quoted a number of references to the disease in animals. In one of these it was asserted that in certain cantons in Switzerland the occurrence of a normal thyroid in the domestic animals is the exception, but Dr Guillebeau, of the Veterinary College at Bern, in an abstract of this article published in the SchweizerArchiv für Thierheilkunde (1888, p. 52), characterises the statements regarding the occurrence of goitre in the Alpine regions as surprising.

In human pathology "goitre" is used as a general term under which are included all cases of thyroid enlargement. This enlargement may be congenital, but more frequently it arises after birth. The enlargement may be due to distension of the blood-vessels of the gland, to simple hypertrophy, i.e., without notable departure from the normal structure of the gland, or to increased proliferation of the normal epithelium and excessive colloid degeneration of the new cells thus 
produced. Enlargement of the thyroid may also be due to true neoplasmatic growth occurring within it.

It will thus be seen that in recording instances of thyroid enlargement in the lower animals, it is desirable that in every case the histology of the morbid gland should be stated.

On reflecting the skin from the region of the throat in this lamb, it

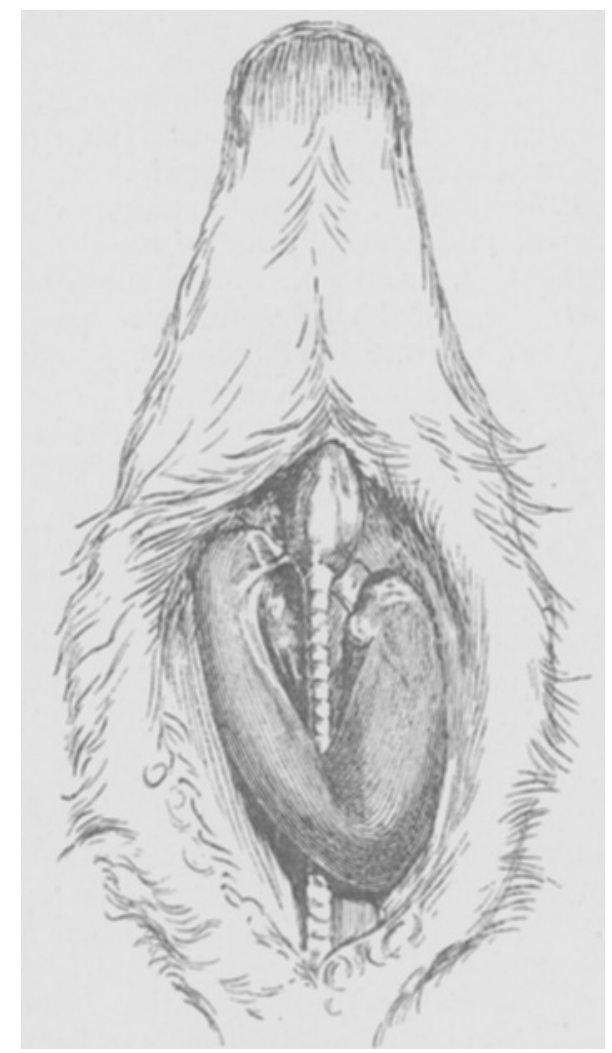

Fı,. 1,-Dissection showing Enlarged Thyroid of Lamb.

was at once apparent that the thyroid gland was greatly enlarged. Its volume may be gathered from the above sketch (Fig. I) and from the statement that it weighed $\mathrm{I} \frac{3}{4}$ ounces. It had a smooth surface, the enlargement appearing to be general, and a pale greyish-red colour. Its consistence was not notably altered. In the dissection from which the above drawing was made, the right and left portions of the gland have been somewhat separated superiorly. The trachea was distinctly compressed between the two divisions of the gland, and this at once furnished an explanation of the dyspnoea. The dysphagia was also clearly ascribable to pressure of the central part of the enlarged gland on the œsophagus (seen to the left of the trachea at the lower part of Fig. I).

The gland having been suitably hardened, sections were made from it and examined microscopically. The annexed figure shows the histology of the gland, which, it may be observed, appeared to be uni- 
form throughout. The case is one of what in human pathology would be termed "colloid goitre." The bulk of the enlarged gland is made up of the so-called colloid substance. This material, which derives its name from its glue-like character, results from a peculiar metamorphosis of cells, generally of epithelial cells. Such a metamorphosis occurs in the normal thyroid, while, as a pathological process, colloid

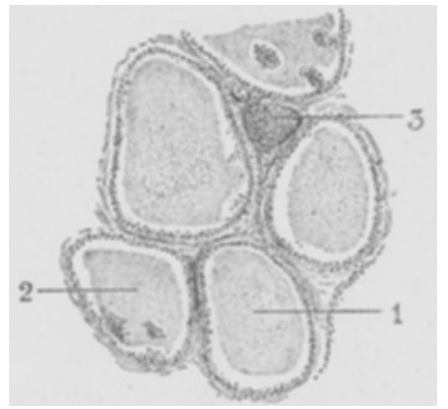

FiG. 2.-Collojd Goitre of Lamb $(x \quad 40)$. 1. A large homogeneous mass of colloid matter; 2 . A mass of colloid matter with two groups of undegenerated epithelium in it; 3 . Section of a small acinus occupied by undegenerated epithelium.

degeneration is common in the epithelium of the carcinomata and in the renal epithelium. In the process of colloid metamorphosis the affected cells become swollen and transformed into rounded masses of a homogeneous, transparent, refractile aspect, and the colloid droplets thus derived from neighbouring cells soon fuse indistinguishably.

In this case the only departures from the normal structure of the gland are (I) the large size of the gland acini, and (2) the abundance of the colloid material. On examining a series of acini the source of the colloid can easily be traced, for all gradations may be found between acini completely filled with undegenerated epithelium, and such as are almost wholly occupied by a homogeneous mass of colloid with distinct epithelium only at the periphery of the acinus. The connective tissue within the gland is sparing in amount and delicate in texture, and there is no discernible distension of blood-vessels.

I have said that the case is one of "colloid goitre," but that is only a sub-variety of hypertrophic goitre. That is to say the primary and fundamental morbid process here is an increased production of the glandular epithelium, and to this hypertrophy there is superadded an excessive colloid transformation of the new cells. $-J . M^{\prime} \mathrm{F}$.]

\section{A CASE OF TRAUMATIC TETANUS*}

\section{By Archibald Baird, M.R.C.V.S., Royal Veterinary College, Edinburgh.}

THE subject of the above was an aged van horse, which had been five weeks under treatment for extensive lacerated wounds on both hips, the result of a run-away. As usually happens in such cases, the wounds from the first took on a healthy action, and were almost healed when, to my disappointment, one day on visiting the patient, 